\title{
Effectiveness of arginine vasopressin for the management of refractory hemorrhagic shock in a patient with autonomic dysreflexia caused by spinal cord injury
}

\author{
Tsukasa Shimauchi $^{1 *}$ D, Jun Maki ${ }^{2}$, Jun Yoshino ${ }^{3}$, Naoyuki Fujimura ${ }^{3}$ and Sumio Hoka ${ }^{4}$
}

\begin{abstract}
Background: Arginine vasopressin has been used for the management of refractory vasodilatory shock. However, it is still unclear whether arginine vasopressin is useful for hypotension in patients with spinal cord injury.

Case description: A 78-year-old man with autonomic dysreflexia and paralysis below the level corresponding to Th2 due to spinal cord injury previously underwent cholecystectomy. During the surgery, accidental hemorrhage led him to refractory hemorrhagic shock unresponsive to fluid resuscitation and catecholamine. Lasting hypotension was improved with arginine vasopressin.
\end{abstract}

Conclusion: We described a rare case report on the use of arginine vasopressin for management of refractory hemorrhagic shock in a patient with autonomic dysreflexia.

Keywords: AVP, Arginine vasopressin, Hemorrhagic shock, Autonomic dysreflexia, Spinal cord injury

\section{Background}

Prolonged hypotension due to marked hemorrhage often progresses to shock that is unresponsive to fluid resuscitation and catecholamines such as norepinephrine [1-3]. Several reports have described the usefulness of arginine vasopressin (AVP) for hemorrhagic shock unresponsive to volume replacement and drug intervention [3-7]. However, there are no reports on the use of AVP for the refractory hemorrhagic shock in patients with autonomic dysreflexia caused by spinal cord injury. Autonomic dysreflexia is a cardiovascular disorder and direct cause of death in patients with spinal cord injury $[8,9]$. It manifests in both the acute and chronic stages of spinal cord injury and becomes refractory in complete injury above the Th6 level [8]. Autonomic dysreflexia leads to cardiac dysfunction because of hyperresponsiveness of overexpression of catecholamine receptors $[9,10]$.

\footnotetext{
* Correspondence: simauci@kuaccm.med.kyushu-u.ac.jp ${ }^{1}$ Operating Rooms, Kyushu University Hospital, 3-1-1 Maidashi, Higashi-ku, Fukuoka 812-8582, Japan

Full list of author information is available at the end of the article
}

Here, we describe a case of catecholamine-resistant hemorrhagic shock treated by AVP in a patient with autonomic dysreflexia caused by spinal cord injury.

\section{Case description}

Written informed consent was obtained from the patient for publication of this case report. A 78-year-old man who had recurrent cholecystolithiasis was scheduled for cholecystectomy. He was paralyzed below the Th2 level due to spinal cord injury caused by traffic accident at the age of 45 . He had clinical features of autonomic dysreflexia such as hypertension, headache, sweating, flushing, and loss of consciousness due to hypotension in the sitting position. Preoperative examination revealed no other abnormalities, and laboratory data were unremarkable. General anesthesia was induced with fentanyl, propofol, and rocuronium, and maintained with propofol, remifentanil, and air-mixed oxygen. Arterial pressure was monitored directly from the radial artery. The systolic and mean arterial pressures (SBP and MAP) were maintained around 100 and $75 \mathrm{mmHg}$, respectively, and the heart rate (HR) was $75 \mathrm{bpm}$. During manual 
dissection of the adhesions around the cystic duct, the inferior vena cava was accidentally injured and marked hemorrhage occurred and then blood pressure had decreased abruptly. Blood loss was replaced with $1500 \mathrm{ml}$ of crystalloid before transfusion of red blood cells and fresh frozen plasma. Phenylephrine and epinephrine bolus, and continuous infusion of norepinephrine $(0.1 \mu \mathrm{g} / \mathrm{kg} / \mathrm{min})$ were performed in order to maintain systolic blood pressure $>70 \mathrm{mmHg}$, a threshold for increased mortality in patients with hemorrhagic shock [11]. Although the inferior vena cava was surgically repaired and hemostasis was almost restored, hypotension (systolic blood pressure $40 \mathrm{mmHg}$ ) persisted. Blood gas data were $\mathrm{pH} 7.19, \mathrm{PaO} 2$ $272 \mathrm{mmHg}$, bicarbonate $11.9 \mathrm{mEq} / \mathrm{l}$, base deficit $-15 \mathrm{mEq} /$ $\mathrm{l}$, and hemoglobin $6.1 \mathrm{~g} / \mathrm{dL}$ (10.1 g/dL before surgery). Thus, we decided to administer AVP and started continuous infusion at $0.2 \mathrm{U} / \mathrm{kg} / \mathrm{min}$, and the hemodynamic status immediately improved. We titrated the infusion rate to $0.02 \mathrm{U} / \mathrm{kg} / \mathrm{h}$ (Fig. 1). $80 \mathrm{mEq}$ of sodium bicarbonate was administered, and fluid resuscitation was continued. The SBP and MAP increased to 110 and $85 \mathrm{mmHg}$ respectively, and the HR was $90 \mathrm{bpm}$. His arterial blood pressure was maintained with $0.02 \mathrm{U} / \mathrm{kg} / \mathrm{h}$ of AVP and $0.02 \mu \mathrm{g} / \mathrm{kg} / \mathrm{min}$ of norepinephrine at the end of the operation. The ABG at this time demonstrated a pH of 7.43, $\mathrm{Pco}_{2}$ of $37 \mathrm{mmHg}, \mathrm{PaO}_{2}$ of $194 \mathrm{mmHg}$, bicarbonate of 17.6 , a base deficit of -7 , and $\mathrm{Hb}$ of $8.5 \mathrm{~g} / \mathrm{dL}$. The total blood loss was $3100 \mathrm{ml}$. For the resuscitation from hypovolemic shock, $2130 \mathrm{ml}$ of blood components was transfused and $3800 \mathrm{ml}$ of crystalloid was administered. The patient was admitted to the intensive care unit with intubated. He had no prolonged hypotension and no neurological complication after surgery.

\section{Discussion}

For the management of patients with hemorrhage shock, volume resuscitation to maintain adequate tissue perfusion takes priority [12]. However, in cases of refractory hemorrhage shock, prolonged hypotension leads to hypoperfusion of the brain and other vital organs. Although vasopressors, such as norepinephrine and dopamine, are useful for maintaining arterial pressure [12], our patient was in a state of hemorrhage shock that was unresponsive to volume resuscitation and catecholamines. This is the first case report describing the use of AVP for the management of refractory hemorrhagic shock in a patient with autonomic dysreflexia caused by spinal cord injury.

Hemorrhagic shock leads to the immediate release of catecholamines, such as epinephrine and norepinephrine, and delayed activation of the renin-angiotensin system as compensatory responses [12]. These compensatory systems may be poorly activated in patients with autonomic dysreflexia. Acidosis followed by hemorrhagic shock inactivates catecholamine receptors and autonomic dysreflexia downregulates catecholamine receptors [8]. Furthermore, prolonged hemorrhagic shock causes vasodilation via the production of nitric oxide (NO) and depletion of stored AVP [7, 12, 13]. Advanced hemorrhagic shock becomes unresponsive to both volume resuscitation and catecholamines because of vasodilatation and acidosis [7, 12]. In cases of hemorrhagic shock unresponsive to

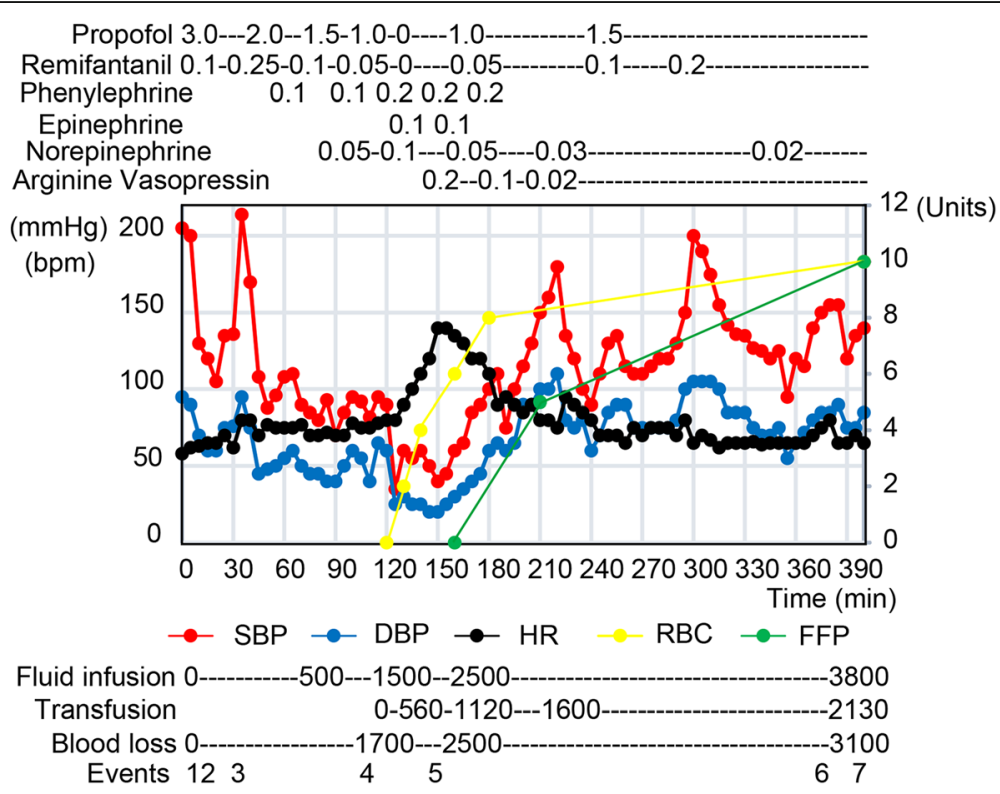

Fig. 1 Anesthetic records for the patient. Propofol: target controlled infusion $(\mu \mathrm{g} / \mathrm{ml})$. Remifentanil: continuous infusion ( $\mu \mathrm{g} / \mathrm{kg} / \mathrm{min})$. Phenylephrine: bolus injection (mg), Epinephrine: bolus injection (mg). Norepinephrine: continuous injection ( $\mu \mathrm{g} / \mathrm{kg} / \mathrm{min})$, Arginine vasopressin: continuous injection $(\mathrm{U} / \mathrm{kg} / \mathrm{h})$. Fluid infusion, transfusion, and blood loss are represented as milliliter. 1, start of anesthesia. 2, tracheal intubation. 3, start of surgery. 4, injury to and 5, repair of the inferior vena cava. 6, end of surgery. 7, end of anesthesia 
catecholamines, vasoconstriction with AVP is an excellent strategy to avoid brain and organ ischemia.

We first administered AVP at $0.2 \mathrm{U} / \mathrm{kg} / \mathrm{h}$ in this case even though this dose is higher than in previous reports [3, 4]. However, there are case reports that describe high-dose AVP for patients with severe hemorrhagic shock [14]. Therefore, we consider $0.2 \mathrm{U} / \mathrm{kg} / \mathrm{h}$ of AVP to be appropriate for patients with severe hemorrhagic shock.

AVP restores vascular tone in a catecholamine-resistant shock state via four known mechanisms: activation of $\mathrm{V}_{1}$ receptors, subtype of AVP receptor found on vascular smooth muscle cells, modulation of ATP sensitive $\mathrm{K}^{+}$ channels, inhibitory action on NO, and potentiation of adrenergic and other vasoconstrictor agents [15]. $\mathrm{V}_{1}$ receptors are highly expressed in vascular smooth muscle and cause vasoconstriction though an increase in intracellular calcium via phosphatidylinositol-bisphosphonate [15]. Inhibition of $\mathrm{NO}$ is effective for hemorrhagic shock that causes vasodilation via NO release [12]. AVP increases systemic vascular resistance without stimulating catecholamine receptors and has no impact on heart rate. AVP also minimally affects pulmonary vascular resistance [16]. For these reasons, AVP is more beneficial than catecholamine for patients with impaired cardiac function [16].

\section{Conclusion}

AVP may be useful for the management of marked hemorrhagic shock that is unresponsive to volume replacement and catecholamines, especially for patients with autonomic dysreflexia caused by spinal cord injury.

\section{Abbreviations}

AVP: Arginine vasopressin; HR: Heart rate; MAP: Mean arterial pressure; NO: Nitric oxide; SBP: Systolic arterial pressure

\section{Acknowledgements}

The authors thank D. Mrozek for his careful reading and editing of the manuscript.

\section{Funding}

The authors declare no funding for this report.

Availability of data and materials

Please contact the author for data requests.

\section{Authors' contributions}

TS performed anesthesia, obtained informed consent from the patient, and wrote the manuscript. MJ supervised the patient and designed the case report. YJ, NF, and SH helped design the case report and edit the manuscript. All authors read and approved the final manuscript.

\section{Ethics approval and consent to participate}

Not applicable.

\section{Consent for publication}

The patient gave written informed consent for publication of this case report.

\section{Publisher's Note}

Springer Nature remains neutral with regard to jurisdictional claims in published maps and institutional affiliations.

\section{Author details}

'Operating Rooms, Kyushu University Hospital, 3-1-1 Maidashi, Higashi-ku, Fukuoka 812-8582, Japan. ${ }^{2}$ Emergency and Critical Care Center, Kyushu University Hospital, Fukuoka, Japan. ${ }^{3}$ Department of Anesthesiology, St Mary's Hospital, Kurume, Japan. ${ }^{4}$ Department of Anesthesiology and Critical Care Medicine, Kyushu University Graduate School of Medical Sciences, Fukuoka, Japan.

Received: 11 September 2018 Accepted: 1 November 2018 Published online: 12 November 2018

\section{References}

1. Mellander S, Lewis DH. Effect of hemorrhagic shock on the reactivity of resistance and capacitance vessels and on capillary filtration transfer in cat skeletal muscle. Circ Res. 1963;13:105-18.

2. Thiemermann C, Szabo C, Mitchell A, Vane JR. Vascular hyporeactivity to vasoconstrictor agents and hemodynamic decompensation in hemorrhagic shock is mediated by nitric oxide. Proc Natl Acad Si U S A. 1993:90:267-71.

3. Morales D, Madigan J, Cullinane $S$, et al. Reversal by vasopressin of intractable hypotension in the late phase of hemorrhagic shock. Circulation. 1999;100(3):226-9.

4. Sharma RM, Setlur R. Vasopressin in hemorrhagic shock. Anesth Analg. 2005; 101:833-4.

5. Liu L, Tian $K$, Xue M, et al. Small doses of arginine vasopressin in combination with norepinephrine "buy" time for definitive treatment for uncontrolled hemorrhagic shock in rats. Shock. 2013;40(5):398-406.

6. Raedler C, Voelckel WG, Wenzel V, et al. Treatment of uncontrolled hemorrhagic shock after liver trauma: fatal effects of fluid resuscitation versus improved outcome after vasopressin. Anesth Analg. 2004;98(6):1759-66.

7. Park KS, Yoo KY. Role of vasopressin in current anesthetic practice. Korean J Anesthesiol. 2017:70(3):245-57.

8. Sharif H, Hou S. Autonomic dysreflexia: a cardiovascular disorder following spinal cord injury. Neural Regen Res. 2017:12(9):1390-400.

9. Davidson R, Phillips A. Cardiovascular physiology and responses to sexual activity in individuals living with spinal cord injury. Top Spinal Cord Inj Rehabil. 2017;23(1):11-9.

10. Lee JS, Fang SY, Roan JN, Jou IM, Lam CF. Spinal cord injury enhances arterial expression and reactivity of alpha1-adrenergic receptors. Spine J. 2016;16:65-71.

11. IMPROVE trial investigators, Powell JT, Hinchliffe RJ, Thompson MM, et al. Observations from the IMPROVE trial concerning the critical care of patients with ruptured abdominal aortic aneurysm. Br J Surg. 2014;101(3):216-24.

12. Gupta B, Garg N, Ramachandran R. Vasopressors: do they have any role in hemorrhagic shock? J Anaesthesiol Clin Pharmacol. 2017;33(1):3-8.

13. Sims CA, Guan Y, Bergey M, et al. Arginine vasopressin, copeptin, and the development of relative AVP deficiency in hemorrhagic shock. Am J Surg. 2017;214(4):589-95.

14. Krismer AC, Wenzel V, Voelckel WG, et al. Employing vasopressin as an adjunct vasopressor in uncontrolled traumatic hemorrhagic shock. Three cases and a brief analysis of the literature. Anaesthesist. 2005;54(3):220-4.

15. Holmes CL, Landy DW, Granton JT. Science review: vasopressin and the cardiovascular system part2-clinical physiology. Crit Care. 2004;8:15-23.

16. Tayama E, Ueda T, Shojima T, et al. Arginine vasopressin is an ideal drug after cardiac surgery for the management of low systemic vascular resistant hypotension concomitant with pulmonary hypertension. Intensive Cardio Vasc Thor Surg. 2007;6:715-9. 